
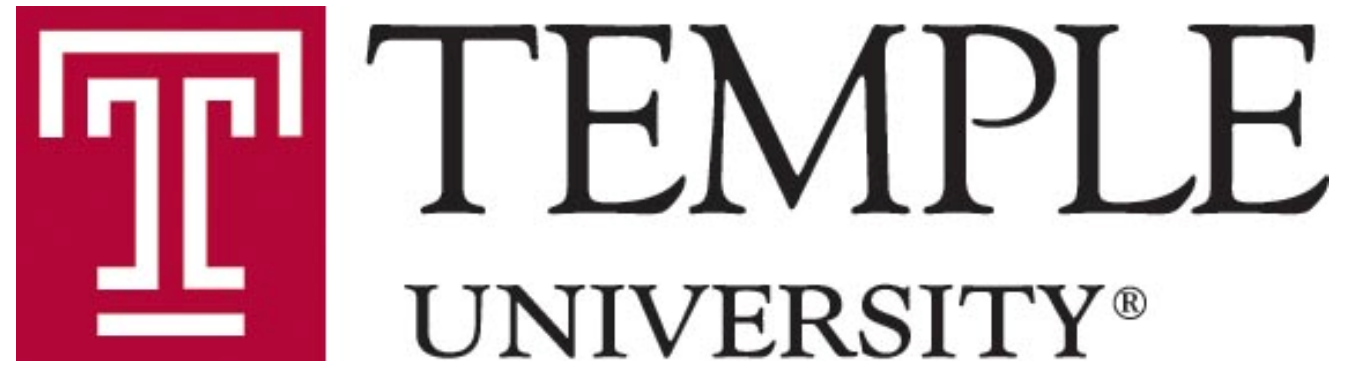

\title{
The Optimum Quantity of Money Revisited: Distortionary Taxation in a Search Model of Money
}

by

Moritz Ritter

Department of Economics

DETU Working Paper 10-05

March 2010

1301 Cecil B. Moore Avenue, Philadelphia, PA 19122

http://www.temple.edu/cla/economics/ 


\title{
The Optimum Quantity of Money Revisited: Distortionary Taxation in a Search Model of Money*
}

\author{
Moritz Ritter ${ }^{\dagger}$
}

January 11, 2010

\begin{abstract}
This paper incorporates a distortionary tax into a microfoundations of money framework and revisits the optimum quantity of money. The money constraint in the decentralized market plays a key role in the optimal policy. Only if the constraint is binding can fiscal policy alter the agents' surplus shares; monetary, but not fiscal, policy affects the agents' bargaining position, leaving a special role for monetary policy. If the buyers surplus share is inefficiently small, the intensive margin is distorted and the constrained optimal policy includes a money growth rate above that prescribed by the Friedman rule, even in the presence of fiscal policy instruments.
\end{abstract}

Keywords: Money; Search; Friedman Rule; Sales Tax

JEL classification: E62, E63, H21

${ }^{*}$ I am grateful to Shouyong Shi for his support and guidance. I have benefited from comments by and discussions with Andres Erosa and Miquel Faig. I also received valuable comments from seminar participants at the University of Toronto, the Midwest Marco Meeting 2007, CEA Meeting 2007 and the 2007 Money, Banking, Payments and Finance Workshop at the Cleveland Fed. All remaining errors and shortcomings are my own.

${ }^{\dagger}$ Department of Economics, Temple University. Email: moritz@temple.edu 


\section{Introduction}

Microfounded models of money, which explicitly model the agents' search decision in the decentralized market, expose a trade-off between the number of transactions (the extensive margin) and the quantity of goods exchanged in each trade (the intensive margin). In these models, agents choose inefficiently low money balances unless the nominal interest rate is zero, i.e. unless the Friedman rule is satisfied (Friedman, 1969). ${ }^{1}$ While this policy minimizes the distortion on the intensive margin, agents' search decisions might be inefficient because agents are not fully compensated for the externalities their search efforts generate. For efficiency on the extensive margin, the agent's surplus share must equal her contribution to the creation of the match, i.e. the Hosios rule (Hosios, 1990) also needs to be satisfied. If the Hosios rule is not satisfied, money growth above the Friedman rule may increase the number of matches and consequently welfare (e.g. Shi, 1997). ${ }^{2}$

These models typically do not study policy instruments other than the monetary ones, so it is unclear how robust this extensive margin effect is to the availability of fiscal policy instruments. This issue was also brought forward by Kocherlakota (2005) in noting that monetary policy alone cannot be expected to fully correct for inefficiencies in an environment with multiple sources of distortions. The present paper addresses this question by incorporating distortionary fiscal policy into a monetary search environment. The key finding is that deviating from the Friedman rule may still result in welfare gains even in the presence of other policy instruments - inflation is not a mere substitute for an omitted fiscal policy. These interactions of monetary and fiscal policies highlight the importance of studying optimal taxation and inflation in an environment in which money is microfounded.

As this paper shows, introducing a sales tax (or production subsidy if the tax rate is negative) into a money search framework (Shi, 1997; Berentsen et al., 2007) helps to correct an inefficiency in the extensive margin. However, if monetary policy obeys the Friedman rule, the buyer's and

\footnotetext{
${ }^{1}$ Berentsen and Rocheteau (2003) provide a detailed discussion of the Friedman rule in search models of money.

${ }^{2}$ Shi $(1998,1999)$ demonstrates the robustness of the extensive margin effect to the introduction of labour market frictions and capital accumulation and Head and Kumar (2005) demonstrate the result holds with price posting. In the Lagos and Wright (2005) framework, the same result arises with price-taking (Rocheteau and Wright, 2005) and with the egalitarian bargaining solution (Aruoba et al., 2007).
} 
seller's surplus shares are unaffected by fiscal policy, which limits the effectiveness of the sales tax alone. In order to improve along the lines of the Hosios rule, the buyer's surplus share needs to approach her contribution to the creation of the match. Thus, deviating from the Friedman rule can be welfare improving even in the presence of a sales tax. By making the money constraint bind, a positive nominal interest rate allows the buyer to extract a larger fraction of the total surplus. This surplus share effect is exclusive to monetary policy. Furthermore, the surplus share effect is not an artefact of the bargaining solution invoked. While the mechanism at play is most clear with bargaining, it is also present with competitive pricing (price taking).

This result also gives some additional insight into the non-monotonicity of the Nash bargaining solution in microfounded models of money. As Aruoba et al. (2007) show, the surplus share of the buyer under Nash bargaining is non-monotone, i.e. the buyer's total surplus is maximized at a quantity smaller than the first best. However, the ineffectiveness of taxation at the Friedman rule shows that the buyer's surplus is not so much non-monotone in the quantity exchanged, but rather in the rate on money growth: were the non-monotonicity driven by the size of the bargaining set per se, the sales tax should increase the buyer's surplus rather than decrease it. The reason for the non-monotonicity is the binding money constraint; under such a constraint, the buyer is naturally limited in her offer, which allows her to extract a larger fraction of the surplus than her exogenous Nash bargaining weight. ${ }^{3}$

The interaction between monetary and fiscal policy has also recently been studied by Aruoba and Chugh $(2006,2008)$ who study the Ramsey problem in a monetary search environment and find that deviating from the Friedman rule is optimal and that the time-path of inflation is stable across the business cycle. Gomis-Porqueras and Peralta-Alva (2009) conduct an analysis closer to that undertaken in this paper by studying optimal fiscal and monetary policy within the Lagos and Wright (2005) framework with exogenous matching rates. They find that, depending on the range of fiscal policy instruments available in the both markets, optimal policy combinations may or may not include a deviation from the Friedman rule. These findings reinforce the result

\footnotetext{
${ }^{3}$ In the LW framework (Lagos and Wright, 2005), which Aruoba et al. (2007) study, the money constraint is always binding with Nash bargaining. A special feature of the Shi (1997) framework is that the constraint is not binding at the Friedman rule. The assumptions that lead to this feature have been questioned, but nevertheless, this feature allows uncovering this property of monetary policy which would be missed in the LW framework.
} 
presented in this paper - that a microfounded environment reveals important interactions between monetary and fiscal policy and that inflation is not a mere substitute for omitted fiscal policy. Rather, fiscal and monetary policy function are complements.

\section{Environment}

\subsection{Households}

The environment strictly follows Berentsen et al. (2007). ${ }^{4}$ The economy is comprised of a large number of households of size measure 1; each household is of a certain type, denoted $h$, with $H>3$ different types in the economy. A household of type $h$ produces good $h$ and consumes good $(h+1)$. Lower case letters denote household level variables, and capital letters denote the corresponding aggregates. Households are made up of two types of agents: buyers and sellers. The fraction of buyers is $n \in(0,1)$. In each period, buyers and sellers enter a decentralized market to search for a trading partner.

All members of the household share the utility generated by the household's consumption. Thus their common objective is to maximize the household's utility, given as follows

$$
U=\sum_{t=0}^{\infty} \beta^{t}\left[u\left(q_{t}^{b}\right)-c\left(q_{t}^{s}\right)-n \phi\left(\sigma_{b t}\right)-(1-n) \phi\left(\sigma_{s t}\right)\right], \quad \beta \in(0,1)
$$

Here $\beta$ is the discount factor, and $c(q)$ the cost of producing $q$ in utility terms. The cost function $c(q)$ satisfies the usual properties $c(0)=0, c^{\prime}(q)>0, c^{\prime \prime}(q)>0$ and $c^{\prime}(0)=0$. The utility function $u(q)$ is assumed to be linear, i.e. the marginal utility $u^{\prime}(q)=u^{\prime}>0$ is constant. ${ }^{5}$ The number of buyers and sellers in the household is denoted by $n$ and $(1-n)$ respectively. The function $\phi(\sigma)$ represents the disutility associated with a search intensity $\sigma \cdot{ }^{6}$ For simplicity, assume $\phi(\sigma)=$ $\phi_{0}\left(\sigma^{\alpha}-1\right)$, with $\phi_{0}>0$ and $\alpha>1$.

\footnotetext{
${ }^{4}$ This is a version of the large household framework by Shi (1997). The other framework commonly used in the microfoundations of money literature is the LW model (Lagos and Wright, 2005). A brief discussion about possible differences in implications can be found in section 6.2 ..

${ }^{5}$ Differently from the LW framework, the assumption of constant marginal utility is not necessary to generate a tractable distribution of money holdings; it solely serves to simplify the problem (Berentsen et al., 2007).

${ }^{6}$ The expressions "search intensity" and "search effort" are used synonymously throughout this paper.
} 
In each period, buyers and sellers enter a the market where they engage in random bilateral matching. Since double coincidence of wants is ruled out by assumption and all members of a certain type of household are indistinguishable, a medium of exchange is needed. In each period $t$, the total stock of money is given by $M_{t} H$, where $M_{t}$ is the average holding of money per household. As sellers have no use for money, all money is carried by the buyers, and each buyer carries $m_{t} / n$ units of money when entering the market. Let $\omega$ denote the value of next period's money to the household and $\Omega$ the value of next period's money to other households. Finally, at the beginning of each period, the government gives a lump-sum transfer $L_{t}$ to each household, so that the money stock grows at a rate of $\gamma$.

\subsection{Fiscal Policy}

Following the traditional money and public finance literature, the fiscal policy instrument is a simple distortionary tax. The tax is modelled as a sales tax, but in this search environment may also be interpreted as an income tax on the seller: whenever a buyer and a seller trade, the government imposes a tax rate $\tau$; i.e. if the buyer pays $x$, the seller receives an after tax total of $x /(1+\tau)$. The tax revenue raised is returned to the agents at the beginning of the next period as a lump-sum transfer to the household. This government transfer has to satisfy

$$
L_{t}=(\gamma-1) M_{t}+\frac{\Psi_{t-1}}{H} \tau x, \quad \gamma \geq \beta
$$

where $\Psi$ denotes the total number of matches. If the tax rate $\tau<0$, this is equivalent to the production subsidy by Gomis-Porqueras and Peralta-Alva (2009). An underlying assumption is that the government is able to monitor the seller's money holdings after the match has taken place.

\subsection{Matching Function}

In the decentralized market, buyers and sellers meet at random, and the total number of trade matches is determined by a matching function $\Psi\left(B \Sigma_{b}, S \Sigma_{s}\right)$, where $B$ denotes the total number 
of buyers and $S$ the total number of sellers in the market; $\Sigma_{i}$ is their average search intensity. $B$ and $S$ are exogenously given as $B=H N$ and $S=H(1-N)$. In contrast, the search intensities are optimally chosen by the households. The function $\Psi($.$) satisfies standard assumptions, such$ as homogeneity of degree 1 and concavity in both arguments (following e.g. Mortensen and Pissarides, 1994 and Berentsen et al., 2007).

It is useful to define the market thickness (for buyers) as the ratio of effective sellers to buyers

$$
T \equiv \frac{S \Sigma_{s}}{B \Sigma_{b}}=\frac{(1-N) \Sigma_{s}}{N \Sigma_{b}}
$$

Denote the marginal contribution of either side to the number of matches as $K_{i}(T)$

$$
K_{i}(T)=\frac{\partial \Psi\left(B \Sigma_{b}, S \Sigma_{s}\right)}{\partial\left(i \Sigma_{i}\right)}, \quad i=B, S
$$

Then, one can rewrite the number of matches as $\Psi\left(B \Sigma_{b}, S \Sigma_{s}\right)=K_{b}(T) B \Sigma_{b}+K_{s}(T) S \Sigma_{s}$. Define the share of buyer's contribution to the total number of matches as

$$
\begin{aligned}
\eta(T)= & K_{b}(T) \frac{B \Sigma_{b}}{\Psi\left(B \Sigma_{b}, S \Sigma_{s}\right)}, \\
& K_{b}(T) \frac{1}{K_{b}(T)+K_{s}(T) T} .
\end{aligned}
$$

and analogously for the seller. Finally, it will prove convenient to define the average matching rate for the buyer and seller as

$$
\begin{aligned}
& A_{b}(T)=\frac{\Psi\left(B \Sigma_{b}, S \Sigma_{s}\right)}{B \Sigma_{b}}=\Psi(1, T), \\
& A_{s}(T)=\frac{\Psi\left(B \Sigma_{b}, S \Sigma_{s}\right)}{S \Sigma_{s}}=\frac{\Psi(1, T)}{T} .
\end{aligned}
$$

\subsection{The Bargaining Process in the Decentralized Market}

The bargaining process is the key mechanism through which fiscal and monetary policy change the agents' search behaviour: in the decentralized market, the buyer is potentially constrained 
by her money holdings. The bargaining outcome will depend on the buyer's money constraint whenever it is binding and, as a result, the bargaining shares of the buyer and seller are endogenous.

After a buyer and a seller meet in the market, they bargain over $q$, the quantity of goods, and $x$, the amount of money to be exchanged in the trade. When making proposals, the agents face two constraints: the buyer's money holdings and the seller's reservation surplus. As in Berentsen et al. (2007), the bargaining process is modeled as a sequential game with an exogenous risk of breakdown. I will focus on the limit case when the time between counteroffers approaches 0 and there is no first-mover advantage; in this case, the solution to the bargaining game becomes the Nash bargaining solution. The bargaining weight of the buyer is denoted $\theta$ and the bargaining weight of the seller $(1-\theta)$. Assuming all agents follow a stationary bargaining strategy, the solution to this bargaining game is summarized in Lemma $1 .^{7}$

Lemma 1. In a symmetric equilibrium, the buyer's surplus is given by

$$
S^{B}(q)=\Theta(q, \tau)[u(q)-c(q)]-\Theta(q, \tau) \tau c(q)
$$

and the seller's surplus is given by

$$
S^{S}(q)=(1-\Theta(q, \tau))[u(q)-c(q)]-(1-\Theta(q, \tau)) \frac{\tau}{(1+\tau)} u^{\prime}(q) q
$$

where $\Theta(q, \tau)$ is defined as

$$
\Theta(q, \tau)=\frac{\theta u^{\prime}(q)}{\theta u^{\prime}(q)+(1+\tau)(1-\theta) c^{\prime}(q)}
$$

As noted above, as a result of the money constraint, the buyer's surplus share $\Theta(q, \tau)$ is endogenous; only if $\theta=0$ (a take-it or leave-it offer by the seller) or if $\theta=1$ (a take-it or leave-it offer by the buyer) does it coincide with $\theta$. The buyer's surplus depends directly on the tax rate and

\footnotetext{
${ }^{7}$ For proof and details see Appendix A.
} 
indirectly through the quantity exchanged in the market, on the rate of money growth. These effects of fiscal and monetary policy are discussed in detail in section 3.2.

\section{The Monetary Equilibrium with Fiscal Policy}

\subsection{The Household's Problem}

In each period, the household chooses its buyers' and sellers' bargaining proposals, their search intensity, and next period's money stock, taking other households' choices as given. The problem can be written as a dynamic programming problem:

$$
v(m)=\max _{\left\{q^{b}, x^{b}, q^{s}, x^{s} \sigma_{b}, \sigma_{s}, m_{+1}\right\}}\left\{\begin{array}{c}
n \sigma_{b} A_{b}(T) u\left(q^{b}\right)-(1-n) \sigma_{s} A_{s}(T) c\left(q^{s}\right) \\
-n \phi\left(\sigma_{b}\right)-(1-n) \phi\left(\sigma_{s}\right)+\beta v\left(m_{+1}\right)
\end{array}\right\}
$$

subject to the law of motion for money

$$
m_{+1}=m+(1-n) \sigma_{s} A_{s}(T) \frac{x^{s}}{(1+\tau)}-n \sigma_{b} A_{b}(T) x^{b}+L
$$

and the surplus and money constraints from the bargaining problem, (A-1) - (A-4).

The resulting first order conditions are given by

$$
\begin{aligned}
u^{\prime}\left(q^{b}\right) & =\frac{\omega+\lambda}{\Omega}(1+\tau) c^{\prime}\left(q^{b}\right) \\
c^{\prime}\left(q^{s}\right) & =\frac{\omega-\pi(1+\tau)}{\Omega(1+\tau)} u^{\prime}\left(q^{s}\right) \\
\phi^{\prime}\left(\sigma_{b}\right) & =A_{b}(T) \Theta(q, \tau)[u(q)-(1+\tau) c(q)] \\
\phi^{\prime}\left(\sigma_{s}\right) & =A_{s}(T) \frac{(1-\Theta(q, \tau))}{(1+\tau)}[u(q)-(1+\tau) c(q)] \\
\frac{\omega_{-1}}{\beta} & =\omega+\sigma_{b} A_{b}(T) \lambda
\end{aligned}
$$

where $\omega=\beta v_{+1}\left(m_{+1}\right)$, the discounted expected value of money next period. $\lambda$ and $\pi$ are the Lagrange multipliers associated with the money constraints on the buyer's (A-1) and seller's (A-3) 
proposal, respectively.

Equation (9) describes the trade-off a proposing buyer faces; the monetary cost of an extra marginal unit of the consumption good is given by $(1+\tau) c^{\prime}\left(q^{b}\right) / \Omega$. This amount of money is valued at $(\omega+\lambda)$ by the buyer, where $\omega$ is next period's value of money and $\lambda$ represents the tighter cash or resource constraint. Thus, the right hand side of (9) represents the marginal cost (in utility terms) of an extra unit of the consumption good for the buyer. The optimal proposal equalizes this marginal cost with the marginal utility. Similarly, equation (10) requires that the marginal gain (in utility terms) is equal to the marginal cost of producing. Equations (11) and (12) describe the optimal choices for the search intensities. The right hand side of each of these equations is the marginal gain from increasing the search intensity, the matching rate per "unit of search effort" times the respective surplus from a trade match. Lastly, (13) is the envelope condition for money.

\subsubsection{Stationary and Symmetric Monetary Equilibrium}

Definition. A stationary and symmetric monetary equilibrium consists of a sequence of individual household's choices $\left\{d_{t}\right\}_{t=0}^{\infty}$, where $d=\left(q^{b}, x^{b}, q^{s}, x^{s}, m_{+1}, \sigma_{b}, \sigma_{s}\right)$, other households' choices $\left\{D_{t}\right\}_{t=0}^{\infty}$, and the shadow prices $(\omega, \Omega, \lambda, \Lambda, \pi, \Pi)$. The sequence satisfies the following requirements for all $t$ :

$i$. optimality: $d_{t}$ solves the households problem given $D_{t}$,

ii. symmetry: $d_{t}=D_{t}$,

iii. stationarity: $d_{t}=d$,

iv. $0<\omega_{t-1} M_{t}<\infty$ and $\omega_{t-1} M_{t}$ constant.

Conditions (i) - (iii) are standard, condition (iv) requires that money has a constant, positive and finite value. ${ }^{8}$

The stationary and symmetric monetary equilibrium allocation $\left(q, \omega x, \sigma_{b}, \sigma_{s}\right)$ can be obtained

\footnotetext{
${ }^{8}$ The existence of an equilibrium was established in Berentsen et al. (2007); it is necessary that $\gamma \geq \beta$ and $\lambda>0$ if and only if $\gamma>\beta$.
} 
from (3), (11), and (12) and the following equations:

$$
\begin{aligned}
\frac{u^{\prime}(q)}{c^{\prime}(q)} & =\left[1+\frac{1}{\sigma_{b} A_{b}(T)}\left(\frac{\gamma}{\beta}-1\right)\right](1+\tau) \\
u(q)-\omega x & =\Theta(q, \tau)[u(q)-(1+\tau) c(q)]
\end{aligned}
$$

Equation (14) comes from combining (9) and (13) and imposing stationarity. Equation (15) follows from Lemma 1.

From (14), we can see that if the economy follows the Friedman rule, $u^{\prime}(q)=(1+\tau) c^{\prime}(q)$. In this case, we can solve for the equilibrium quantity without having to specify the matching function. It is obvious that only if $\tau=0$, the intensive margin will be undistorted. If $\tau \neq 0$, the quantity $q$ deviates from the social optimum even if $\gamma=\beta .^{9}$ From (14) it also follows that deviating from the Friedman rule will result in an inefficiency in the intensive margin. This follows directly from the fact that the buyer is constrained by his real money balances. Whenever $\gamma>\beta$, there is an opportunity cost of holding money and hence the buyer will choose to hold inefficiently low real money holdings; $q$ will thus also be inefficiently low.

\subsection{The Buyer's Surplus Share Revisited}

Recall from Lemma 1 that the buyer's fraction of the surplus is given by $\Theta(q, \tau)$. Using the steady state condition (14), $\Theta(q, \tau)$ can be rewritten as

$$
\Theta(\gamma, \tau)=\frac{\theta}{\theta+\frac{(1-\theta)}{\left[1+\frac{1}{\sigma_{b} A_{b}(T)}\left(\frac{\gamma}{\beta}-1\right)\right]}} .
$$

From (16), it can be seen that the buyer's surplus share critically depends on the rate of money growth. If monetary policy follows the Friedman rule, $\Theta(\gamma, \tau)$ reduces to $\theta$, the exogenous bargaining weight. This implies that at the Friedman rule, the surplus split is independent of the fiscal policy; the buyer receives a fixed fraction of the total surplus regardless of the tax rate $\tau$.

The buyer's surplus share becomes endogenous only if monetary policy deviates from the

\footnotetext{
${ }^{9}$ See section 4 for the characterization of the social optimum.
} 
Friedman rule: from (16), it follows that $\Theta(\gamma, \tau)$ is increasing in the rate of money growth. Equivalently, examining (10) shows that the higher the rate of money growth, the tighter the money constraint and the larger the Lagrange multipliers $\lambda / \omega$ and $\pi / \omega$. Substituting (10) into $\Theta(q, \tau)$ shows that the buyer's surplus share is increasing in $\pi / \omega$, i.e. the higher the rate of money growth, the larger the buyer's surplus share.

The intuition for this result follows from the latter argument. The money constraint serves as a credible upper bound to the buyer's offer and becomes tighter as the rate of money growth increases. This improves the buyer's threat point in the bargaining game and allows her to extract a larger fraction of the total surplus, creating the surplus share effect of monetary policy.

This result is related to the non-monotonicity of the Nash bargaining solution discussed by Aruoba et al. (2007). The authors show that the buyer's surplus under Nash bargaining is maximized at a quantity $q$ less than the first best. As the quantity exchanged falls (in the neighborhood of the first best), the buyer receives a larger fraction of a smaller surplus, increasing the buyer's total surplus. However, as the result above shows, the buyer's surplus is not always nonmonotone in $q$. At the Friedman rule, the buyer's surplus falls as the quantity and total surplus decrease because of the sales tax. The reason for the non-monotonicity is the binding money constraint in the bargaining process; the tighter the constraint, the larger the buyer's surplus share. Only when the constraint is binding is the buyer's surplus non-monotone.

The surplus share effect of monetary policy is also essential for the effectiveness of fiscal policy. A positive tax rate has three effects on the buyers' surplus, (5):

1. It lowers total surplus $[u(q)-c(q)]$ by lowering $q$.

2. It levies a tax burden on buyers: $[\Theta(\gamma, \tau) \tau c(q)]$.

3. It changes the buyer's share of the total surplus: $\frac{\partial \Theta(\gamma, \tau)}{\partial \tau} \leq 0$.

However, at the Friedman rule, the last effect is not active, $\Theta(\gamma=\beta, \tau)=\theta$. If, however, the rate of money growth exceeds the rate of time preference $(\gamma>\beta)$, the sales tax will further improve the buyer's bargaining position. To see this, note that $\sigma_{b} A_{b}(T)$ decreases as $\tau$ increases. ${ }^{10}$ The

\footnotetext{
${ }^{10} \sigma_{b} A_{b}(T)$ is the probability of the buyer to find a seller. As the market tightness $T$ decreases, the matching probability for the falls.
} 
intuition is the same as for monetary policy: if the buyer is constrained by her money holdings, increasing the tax rate makes this constraint even more binding, allowing the buyer to extract a larger fraction of the total surplus. However, this channel only works if the buyer's money constraint is binding, highlighting the special role of money that cannot be replicated by fiscal policy.

\section{Social Optimum}

Now consider the problem of a benevolent planner who seeks to maximize social welfare - the total trade surplus generated by all matches, less the cost of searching incurred to create these matches. Hence, the social welfare function can be written as

$$
W=\Psi\left(N \Sigma_{b},(1-N) \Sigma_{s}\right)[u(q)-c(q)]-N \phi\left(\Sigma_{b}\right)-(1-N) \phi\left(\Sigma_{s}\right)
$$

The planner chooses the quantity produced in each match, $q$, and agents' search intensities $\left(\Sigma_{b}, \Sigma_{s}\right)$. The first order conditions are given by

$$
\begin{aligned}
u^{\prime}(q) & =c^{\prime}(q) \\
\phi^{\prime}\left(\Sigma_{b}\right) & =K_{b}(T)(u(q)-c(q))=\eta(T) A_{b}(T)(u(q)-c(q)) \\
\phi^{\prime}\left(\Sigma_{s}\right) & =K_{s}(T)(u(q)-c(q))=(1-\eta(T)) A_{s}(T)(u(q)-c(q)) .
\end{aligned}
$$

The social optimum $\left(q^{*}, \Sigma_{b}^{*}, \Sigma_{s}^{*}\right)$ is characterized by (18) - (20) and (3).

In comparing the social optimum characterized by (18) - (20) and the monetary equilibrium characterized above, several differences are apparent: the quantity, and the search intensities, may differ. From (18) and (14), it follows that in order for the quantity traded to be efficient, the tax rate must be zero and monetary policy needs to follow the Friedman rule.

Moreover, comparing (11) to (19) and (12) to (20), it follows that efficiency in the number of trades requires $\Theta(q, \tau)=\eta(T)$ : the buyer's surplus share needs to equal her contribution to the creation of the match. Since $\Theta(q, \tau)$ reduces to $\theta$ at the Friedman rule, the Hosios rule calls for 
$\theta=\eta\left(T^{*}\right)$. However, there is no apparent reason to believe that this requirement is satisfied, since this condition links a property of the matching function to the buyer's bargaining power. If $\theta<\eta\left(T^{*}\right)$, the buyer's bargaining share is too small and her search intensity too low. ${ }^{11}$ In order to improve efficiency, $\sigma_{b}$ needs to increase relative to $\sigma_{s}$, so $T$ needs to decrease. Conversely, if $\theta>$ $\eta\left(T^{*}\right)$, the equilibrium market thickness is too low and an increase in $T$ will improve efficiency.

\section{The Welfare Effects of Fiscal and Monetary Policy}

From the previous sections, it is evident that the monetary equilibrium is unlikely to coincide with the first best outcome if there is no fiscal policy and monetary policy simply follows the Friedman rule. This section studies how fiscal and monetary policy can improve efficiency in this environment and demonstrates that monetary, but not fiscal, policy alters the agents' bargaining position, rendering a deviation from the Friedman rule optimal whenever the buyer's bargaining weight is small relative to her contribution to the match. This result is summarized in the following proposition.

Proposition 1. If $\theta<\eta\left(T^{*}\right), \tau^{*}>0$ and $\gamma^{*}>0$, the optimal policy calls for a positive sales tax and a deviation from the Friedman rule.

The proof is laid out in three parts. First, section 5.1 derives the optimal tax rate at the Friedman rule. Section 5.2 then establishes that, it is optimal to deviate from the Friedman rule if $\theta<\eta\left(T^{*}\right)$ without fiscal policy. Lastly, section 5.3 combines the previous two results and proves that an optimal policy mix consists of using the two instruments jointly.

\subsection{Fiscal Policy}

If the buyer's bargaining weight is too low relative to her contribution to the match $\left(\theta<\eta\left(T^{*}\right)\right)$, the buyer is not sufficiently rewarded for her search effort and will hence choose an inefficiently low search effort. This renders the market tight for sellers and thick for buyers, i.e. $T$ is inefficiently high. In order to improve efficiency, any policy needs to decrease the market tightness.

\footnotetext{
${ }^{11}$ To see this, compare (11) to (19) with $\tau=0$ and note that $\phi(\sigma)$ is a convex function.
} 
To see that the market tightness decreases as the tax rate increases, divide (11) by (12) and impose the Friedman rule:

$$
T_{\mid \gamma=\beta}=\left[\left(\frac{(1-N)}{N}\right)^{\alpha-1}\left(\frac{(1-\theta)}{\theta}\right) \frac{1}{(1+\tau)}\right]^{\frac{1}{\alpha}}
$$

From (21), it follows that the market tightness at the Friedman rule is decreasing in the tax rate: $\left.\frac{\partial T}{\partial \tau}\right|_{\gamma=\beta}<0$. Now, taking the derivative of the welfare function (17) with respect to the tax rate and evaluating at the Friedman rule gives

$$
\begin{aligned}
{\left.\frac{\partial W}{\partial \tau}\right|_{\gamma=\beta}=} & \Psi \tau\left[c^{\prime} \frac{\partial q}{\partial \tau}+\left(\theta \frac{1}{\Sigma_{b}} \frac{\partial \Sigma_{b}}{\partial \tau} c(q)+\frac{(1-\theta)}{(1+\tau)} \frac{1}{\Sigma_{s}} \frac{\partial \Sigma_{s}}{\partial \tau} u(q)\right)\right] \\
& +\Psi(\eta(T)-\theta) \frac{\Sigma_{s}}{\Sigma_{b}} \frac{\partial\left(\frac{\Sigma_{b}}{\Sigma_{s}}\right)}{\partial \tau}(u-c) \\
= & \Psi \frac{1}{T} \frac{\partial T}{\partial \tau}\left[-(\eta(T)-\theta)(u-c)+\tau\left(\begin{array}{c}
\alpha \frac{\left(c^{\prime}\right)^{2}}{c^{\prime \prime}}+\frac{\theta}{\alpha-1} c(q)\left((1-\eta)+\alpha \frac{(1+\tau) c}{u-(1+\tau) c}\right) \\
+\left(\frac{1-\theta}{1+\tau}\right) \frac{1}{\alpha-1} u(q)\left(-\eta+\alpha \frac{(1+\tau) u}{u-(1+\tau) c}\right)
\end{array}\right)\right] .
\end{aligned}
$$

Since $\frac{\partial T}{\partial \tau}<0,(22)$ indicates that $\tau_{\mid \gamma=\beta}^{*}>0$ if and only if $\theta<\eta(T)$. The optimal tax rate at the Friedman rule, $\tau_{\mid \gamma=\beta}^{*}$ then solves

$$
(\eta(T)-\theta)(u-c)=\tau\left(\begin{array}{c}
\alpha \frac{\left(c^{\prime}\right)^{2}}{c^{\prime \prime}}+\frac{\theta}{\alpha-1} c(q)\left((1-\eta)+\alpha \frac{(1+\tau) c}{u-(1+\tau) c}\right) \\
+\left(\frac{1-\theta}{1+\tau}\right) \frac{1}{\alpha-1} u(q)\left(-\eta+\alpha \frac{(1+\tau) u}{u-(1+\tau) c}\right)
\end{array}\right)
$$

As discussed above, the sales tax has three effects on the agents' surpluses. The sales tax reduces total surpluses because it distorts the quantity of goods exchanged and it levies a tax burden on both buyer and seller. The third effect, a change in the surplus split between buyer and seller, is not present here. At the Friedman rule, the buyer's surplus share is equal to $\theta$, and is independent of the tax rate $\tau$. As a result, both the buyer's and seller's surplus fall and 
their search intensities decrease. However, the seller's search effort falls relatively more than the buyer's. This is because an increase in the tax rate reduces the present value of the amount of money exchanged in the match, $\omega x /(1+\tau)$, making it relatively less attractive to be a seller and consequently lowering the market tightness. Therefore, if $\theta<\eta(T)$ (i.e. if the exogenous bargaining share of the buyer is too small), imposing a sales tax increases welfare and if $\theta>\eta(T)$, paying a subsidy improves welfare. This is a typical second best result - the second order loss in the intensive margin is smaller than the first order gain in the extensive margin. Yet, since the surplus shares are unchanged, fiscal policy is rather limited in the extend it helps to improve along the Hosios rule.

\subsection{Monetary Policy}

To see how $T$ responds to an increase in the rate of money growth, combine the equilibrium conditions (19) and (14) to obtain

$$
\left(\frac{\gamma}{\beta}-1\right)^{\alpha-1}=\left(\frac{u^{\prime(q)}}{c^{\prime}(q)(1+\tau)}-1\right)^{\alpha-1} \frac{\left[A_{b}(T)\right]^{\alpha}(u(q)-(1+\tau) c(q))}{\alpha \phi_{0}\left(1+T^{\alpha}(1+\tau)\left(\frac{N}{1-N}\right)^{\alpha-1}\right)}
$$

After solving for $q=q(T)$ by dividing (11) by (12) and substituting into (24), the resulting expression gives $\frac{\partial T}{\partial \gamma}<0$. This is a result of the surplus share effect described above. That is, if the rate of money growth exceeds the Friedman rule, the buyer becomes constrained by her money holdings, which allows her to credibly limit her offer to the seller, thus increasing her share of the total surplus. As a result, the buyer's search effort increases relative to the seller's effort and the market tightness $T$ decreases.

To analyze the welfare effect of increasing the rate of money growth above the rate prescribed by the Friedman rule, take the derivative of the welfare function (17) with respect to $\gamma$ and evaluate at $\gamma=\beta$ : 


$$
\begin{aligned}
{\frac{\partial W}{\partial \gamma}{ }_{\mid \gamma=\beta}=} & \Psi \tau\left[c^{\prime} \frac{\partial q}{\partial \gamma}+\left(\theta \frac{1}{\Sigma_{b}} \frac{\partial \Sigma_{b}}{\partial \gamma} c(q)+\frac{(1-\theta)}{(1+\tau)} \frac{1}{\Sigma_{s}} \frac{\partial \Sigma_{s}}{\partial \gamma} u(q)\right)\right] \\
& +\Psi(\eta(T)-\theta) \frac{\Sigma_{s}}{\Sigma_{b}} \frac{\partial\left(\frac{\Sigma_{b}}{\Sigma_{s}}\right)}{\partial \gamma}(u-c) \\
= & \Psi \frac{1}{T} \frac{\partial T}{\partial \gamma}\left[-(\eta(T)-\theta)(u-c)+\tau\left(\begin{array}{c}
\alpha \frac{\left(c^{\prime}\right)^{2}}{c^{\prime \prime}}+\frac{\theta}{\alpha-1} c(q)((1-\eta)-\alpha(1-\theta)) \\
+\left(\frac{1-\theta}{1+\tau}\right) \frac{1}{\alpha-1} u(q)(-\eta+\alpha \theta)
\end{array}\right)\right]
\end{aligned}
$$

With $\tau=0$, there is a positive effect of increasing the rate of money growth at the Friedman rule when $\theta<\eta(T)$. As described above, deviating from the Friedman rule raises the buyer's share of the surplus by tightening the money constraint. In the neighborhood of the first best quantity, this increases the buyer's and decreases the seller's surplus and hence improves welfare if the buyer's search effort is inefficiently small relative to the seller's effort. If, however, $\theta>\eta(T)$, the Friedman rule is still constrained optimal. In this case, the Hosios rule demands a negative nominal interest rate which is not a feasible policy option.

\subsection{Optimal Policy Mix}

It is apparent that both fiscal and monetary policy in isolation will be welfare improving, at least if $\theta<\eta(T)$. And while in isolation monetary policy is more effective since it actually alters the surplus shares, the key question remains: is the Friedman rule optimal in the presence of fiscal policy, and how does the optimal policy mix $\left(\gamma^{*}, \tau^{*}\right)$ compare to the optimal rate of money growth in an environment without a sales tax?

To answer the first question, set $\tau=\tau_{\mid \gamma=\beta}^{*}$ in the first order condition for the rate of money growth evaluated at the Friedman rule (25). Using (23), the resulting expression can be simplified to 


$$
W_{\gamma}\left(\tau_{\mid \gamma=\beta}^{*}, \beta\right)=\frac{1}{T} \frac{\partial T}{\partial \gamma} \tau^{*}\left(\begin{array}{c}
\theta \frac{\alpha}{\alpha-1} c(q)\left(-(1-\theta)-\frac{\left(1+\tau^{*}\right) c}{u-\left(1+\tau^{*}\right) c}\right) \\
+\left(\frac{1-\theta}{1+\tau^{*}}\right) \frac{\alpha}{\alpha-1} u(q)\left(\theta-\frac{\left(1+\tau^{*}\right) u}{u-\left(1+\tau^{*}\right) c}\right)
\end{array}\right)<0 \text { if } \theta<\eta
$$

Since both $\frac{\partial T}{\partial \gamma}$ and the expression in round brackets are negative, the sign of (26) is the same as $\tau_{\mid \gamma=\beta}^{*}$. As shown above, $\tau_{\mid \gamma=\beta}^{*}>0$ if $\theta<\eta$; hence with distortionary taxation, increasing the rate of money growth above the rate of time preference is still welfare improving if the buyer's bargaining power is lower than her contribution to the match creation. Thus, the conditions for the suboptimality of the Friedman rule are the same as without fiscal policy.

To understand this optimal policy, recall that once the money growth exceeds the rate of time preference, the sales tax will further improve the buyer's bargaining position. On its own, monetary policy is more efficient since it can actually alter the surplus shares towards the ones demanded by the Hosios rule. However, after the money constraint binds, fiscal policy further increases the buyer's surplus share. In that sense, money and fiscal policies are complementary, with the surplus share effect of monetary policy leaving a special role for monetary policy.

\section{Discussion}

\subsection{Competitive Pricing}

In monetary search models, a variety of pricing mechanisms other than bargaining have been used. I will briefly discuss competitive pricing (price-taking) to further illustrate how the key to the suboptimality of the Friedman rule is the ability of monetary policy to increase the buyer's surplus.

With price taking, the search friction is modelled as entry into a specific market for good $h$. Once in the market, buyers and sellers observe the price $p$ and the buyer demands $q^{b}$ while the seller offers $q^{s}$. To make the two models comparable, let the entry function be the matching function described earlier; in this case, the number of buyers equals the number of sellers in the market. Then, the probability of a buyer entering the market is the same as her finding a 
trading partner in the environment with bilateral matching and bargaining, $A_{b}(T) \sigma_{b}$; similarly, the probability of trading for the seller is $A_{s}(T) \sigma_{s}$.

In the resulting stationary equilibrium, the buyer's and seller's surplus are given by: ${ }^{12}$

$$
\begin{aligned}
S^{B}(q) & =u(q)-u^{\prime}(q) q+\frac{1}{\sigma_{b} A_{b}(T)}\left(\frac{\gamma}{\beta}-1\right)(1+\tau) c^{\prime}(q) \\
\text { and } \quad S^{S}(q) & =c^{\prime}(q) q-c(q) .
\end{aligned}
$$

From (27) it is apparent that as with Nash bargaining, at the Friedman rule the buyer's surplus is increasing in $q$ and hence decreasing in $\tau$; the same is true for the seller's surplus. Hence, with fiscal policy, the buyer's and seller's surplus move in the same direction. Conversely, money growth may increase the buyer's surplus, while it always decreases the seller's surplus - as with Nash bargaining, money has a surplus share effect.

While it is not possible to derive specific conditions for an optimal policy mix without specifying functional forms for $u(q)$ and $c(q)$, one can see from (27) that with (almost) constant marginal utility the buyer's surplus is (almost) zero at the Friedman rule. This is because in that case demand is very elastic which results in the seller extracting (almost) the entire surplus. Imposing a sales tax has no impact on the buyer's surplus, whereas increasing the rate of money growth above the Friedman rule does. The positive opportunity cost of carrying money makes the buyer economize on her holdings, lowering the quantity exchanged and hence the marginal cost of producing and the resulting market price. As with bargaining, restricting the buyer's money holdings allows him to extract a larger share of the total surplus.

\subsection{Comparison to the Lagos-Wright Framework}

The other framework commonly used in the microfoundations literature is the so-called LW framework (Lagos and Wright, 2005). A key difference from the model above is that buyer's money constraint is binding even if the planner follows the Friedman rule. Consequently, the buyer's surplus share is always endogenous. Since the intensive margin is distorted at the Fried-

\footnotetext{
${ }^{12}$ See Appendix B for details.
} 
man rule, it depends on the exact functional forms of cost and utility functions whether a sales tax and/or monetary policy can improve welfare by alleviating an inefficiency in the extensive margin. ${ }^{13}$

Nevertheless, the key result that monetary and fiscal policy are not mere substitutes because only monetary policy has the ability to alter the surplus share carries through into the LW framework. Under bargaining this effect cannot be seen because of the binding money constraint at the Friedman rule. However, as Rocheteau and Wright (2005) show, with price taking as the pricing mechanism the buyer is unconstrained and the intensive margin is undistorted at the Friedman rule; in that case, a deviation from the Friedman rule can be optimal if the buyer's surplus share is inefficiently small. Implementing the same sales tax as above leads to an identical solution for the buyer's surplus under price taking as in the Shi model used in this paper: ${ }^{14}$

$$
S^{B}(q)=u(q)-u^{\prime}(q) q+\frac{1}{\alpha_{b}(n)}\left(\frac{\gamma}{\beta}-1\right)(1+\tau) c^{\prime}(q)
$$

where $\alpha_{b}(n)$ denotes the average matching rate. Again, it is apparent that an increase in the rate of money growth can increase the buyer's total surplus which fiscal policy cannot accomplish at the Friedman rule. Hence, if $u(q)$ is close to linear (i.e. $S^{B}$ is too small) and the buyer's search decision is explicitly modelled, a deviation from the Friedman rule and not a sales tax would be the optimal policy prescription.

\section{Conclusion}

This paper introduces a sales tax into the monetary search framework. A departure from the Friedman rule is optimal whenever there is a thick market on the buyer's side, i.e., if there are too many sellers relative to buyers in the market. The deviation from the Friedman rule causes the buyer to restrict her money balance, changing the agents' bargaining position and allowing the buyers to extract a larger fraction of the trade surplus. A sales tax cannot reproduce this

\footnotetext{
${ }^{13}$ See Gomis-Porqueras and Peralta-Alva (2009) for a detailed discussion of optimal monetary and fiscal policies in the LW framework under Nash bargaining.

${ }^{14}$ See Appendix $\mathrm{C}$ for details.
} 
surplus share effect, leaving a special role for monetary policy. Moreover, this finding does not depend on bargaining as the pricing mechanism; this surplus share effect is also present in an an environment with competitive pricing.

This results highlights the importance of using microfounded models of money to study issues such as the optimal quantity of money and the Ramsey problem, something the traditional money and public finance literature (e.g. Kimbrough, 1986, Faig, 1988, Correia and Teles, 1996 and Chari et al., 1996) has not done. The result also highlights the underlying mechanism behind the non-monotonicity of the buyer's surplus under Nash bargaining, which causes the equilibrium in the Lagos and Wight (2005) framework to be inefficient, even under the Friedman rule.

This paper focuses only on the scenario in which the buyer's contribution to the creation of the match exceeds the exogenous Nash bargaining weight. In that case, deviating from the Friedman rule can improve efficiency because it increases the buyer's surplus share above her exogenous bargaining parameter. In the opposite situation, the exogenous bargaining parameter is the lower bound for the buyer's surplus share; a negative nominal interest rate is not a feasible policy option, so the Friedman rule is the constrained optimal policy. However, fiscal policy can achieve some welfare improvement by setting a negative tax rate - paying a subsidy to the agents. 


\section{References}

[1] Aruoba, Boragan S. and Sanjay K. Chugh (2006): “Optimal Fiscal and Monetary Policy when Money is Essential." Working Paper, University of Maryland.

[2] Aruoba, Boragan S. and Sanjay K. Chugh (2008): "Money and Optimal Capital Taxation.” Working Paper, University of Maryland.

[3] Aruoba, Boragan S., Guillaume Rocheteau and Christopher J. Waller (2007): "Bargaining and the Value of Money." Journal of Monetary Economics, Vol. 54, pp. 2636-2655.

[4] Berentsen, Aleksander and Guillaume Rocheteau (2003): "On the Friedman Rule in Search Models of Money." Contributions to Macroeconomics, Vol. 3, pp. 1-19.

[5] Berentsen, Aleksander, Guillaume Rocheteau and Shouyong Shi (2007): "Friedman Meets Hosios: Efficiency in Search Models of Money.” Economic Journal, Vol. 117, pp.174-195.

[6] Chari, V. V., Lawrence Christiano and Patrick Kehoe (1996): "Optimality of the Friedman Rule in Economies with Distorting Taxes.” Journal of Monetary Economics, Vol. 38, pp. 203-233.

[7] Faig, Miquel (1988): "Characterization of the Optimal Tax on Money when it Functions as a Medium of Exchange.” Journal of Monetary Economics, Vol. 22, pp. 137-148.

[8] Friedman, Milton (1969): “The Optimum Quantity of Money.” in: Friedman, Milton, The Optimum Quantity of Money and Other Essays, Chicago: Aldine.

[9] Gomis-Porqueras, Pere and Adrian Peralta-Alva (2009): "Optimal Monetary and Fiscal Policies in a Search Theoretic Model of Monetary Exchange." European Economic Review, forthcoming.

[10] Head, Allen and Alok Kumar (2005): "Price Dispersion, Inflation, and Welfare." International Economic Review, Vol. 46, pp. 533-572.

[11] Hosios, Arthur J. (1990): "On the Efficiency of Matching and Related Models of Search and Unemployment.” Review of Economic Studies, Vol. 57, pp. 279-298.

[12] Kimbrough Kent P. (1986): “The Optimum Quantity of Money Rule in the Theory of Public Finance,” Journal of Monetary Economics, Vol. 18, pp. 277-284.

[13] Kocherlakota, Narayana (2005): “Optimal Monetary Policy: What We Know and What We Don't Know.” International Economic Review, Vol. 46, pp. 715-729.

[14] Lagos, Ricardo and Randall Wright (2005): "A unified framework for monetary theory and policy analysis." Journal of Political Economy, Vol. 113, pp. 463-484.

[15] Phelps, Edward (1973): "Inflation in the Theory of Public Finance." Swedish Journal of Economics, Vol. 75, pp. 67-82.

[16] Rocheteau, Guillaume and Randall Wright (2005): "Money in Search Equilibrium, in Competitive Equilibrium, and in Competitive Search.” Econometrica, Vol. 73, pp. 175-202.

[17] Shi, Shouyong (1997): “A Divisible Model of Fiat Money.” Econometrica, Vol. 65, pp. 75-102.

[18] Shi, Shouyong (1998): "Search for a Monetary Propagation Mechanism." Journal of Economic Theory, Vol. 81, pp. 314-352.

[19] Shi, Shouyong (1999): "Search, Inflation and Capital Accumulation." Journal of Monetary Economics, Vol. 44, pp. 81-103. 


\section{APPENDIX A: The Bargaining Problem}

The buyer and seller bargain over $q$ (quantity of goods) and $x$ (amount of money to be exchanged). The bargaining process is modeled as a sequential game with an exogenous risk of breakdown. In each round, one agent proposes a pair $(q, x)$ and the respondent accepts or rejects. If the proposal is accepted, the trade takes place immediately on the agreed upon terms; if not, time $\Delta$ elapses and the respondent may make a counteroffer. During this "waiting time", the game might break down; the probability of breakdown depends on the rejecting agent's type. If a seller rejects the buyer's offer, the probability of breakdown is $\theta \Delta$; if the buyer rejects the seller's proposal, the probability is $(1-\theta) \Delta$, where $\theta \in(0 ; 1)$. I consider the limit case when $\Delta$ approaches 0 , and there is no first-mover advantage.

Assume all agents follow a stationary bargaining strategy, i.e. a buyer always proposes $\left(q^{b}, x^{b}\right)$ and a seller always proposes $\left(q^{s}, x^{s}\right)$. First, consider the buyer's problem: when making her proposal, the buyer faces two constraints. She is restricted by her own money holdings, and she may not leave the seller less surplus than his reservation surplus. Upon accepting, the seller obtains $x^{b}$ units of money with a present value of $\Omega x^{b}$ and incurs a disutility of $c\left(q^{b}\right)$. Hence, his surplus from accepting is $\left[\Omega x^{b}-c\left(q^{b}\right)\right]$. If he decides to reject, he will make a counteroffer $\left(Q^{s}, X^{s}\right)$ with probability $(1-\theta \Delta)$ that gives him a surplus of $\left[\Omega X^{s}-c\left(Q^{s}\right)\right]$.

So, the buyer's proposal must satisfy

$$
\begin{aligned}
\frac{m}{n} & \geq x^{b} \\
\Omega x^{b} /(1+\tau)-c\left(q^{b}\right) & \geq(1-\theta \Delta)\left[\Omega X^{s} /(1+\tau)-c\left(Q^{s}\right)\right]
\end{aligned}
$$

and the seller's proposal needs to satisfy

$$
\begin{aligned}
\frac{M}{N} & \geq x^{s} \\
u\left(q^{s}\right)-\Omega x^{s} & \geq(1-(1-\theta) \Delta)\left[u\left(Q^{b}\right)-\Omega X^{b}(1+\tau)\right] .
\end{aligned}
$$

In equilibrium, (A-2) and (A-4) will be satisfied with equality. To see why, suppose to the contrary that (A-2) holds as a strict inequality; the buyer could increase her utility by rising $q^{b}$ without increasing $x^{s}$ until the constraint is satisfied with equality. Likewise, the seller could decrease $q^{s}$ and hence his disutility of production if (A-4) were not satisfied with equality.

Rearranging the constraints gives

$$
\begin{aligned}
Q^{s} & =Q^{s}\left(q^{b}, \Delta\right)=\frac{1}{u^{\prime}}\left[\omega \frac{m}{n}+(1-(1-\theta) \Delta)\left(u^{\prime} q^{b}-\omega x^{b}\right)\right] \\
\frac{\partial}{\partial \Delta} Q^{s}\left(q^{b}, \Delta\right) & =-\frac{1-\theta}{u^{\prime}}\left[u^{\prime} q^{b}-\omega \frac{m}{n}\right] .
\end{aligned}
$$

In equilibrium $Q^{s}\left(q^{b}, 0\right)=q^{b}$, so

$$
\Omega \frac{m / n}{1+\tau}-c\left(q^{b}\right)=(1-\theta \Delta)\left[\Omega \frac{m / n}{1+\tau}-c\left(Q^{s}\left(q^{b}, \Delta\right)\right)\right],
$$

which can be rearranged to

$$
\theta \Omega \frac{m / n}{1+\tau}=\frac{1}{\Delta}\left[c\left(q^{b}\right)-(1-\theta \Delta) c\left(Q^{s}\left(q^{b}, \Delta\right)\right)\right] .
$$

Take limit $\Delta \rightarrow 0$

$$
\theta \Omega \frac{m / n}{1+\tau}=\theta c\left(q^{b}\right)-c^{\prime} \frac{-(1-\theta)}{u^{\prime}}\left[u^{\prime} q^{b}-\omega \frac{m}{n}\right],
$$


which can be rearranged to

$$
\omega \frac{m}{n}=\frac{(1+\tau) u^{\prime}}{\theta u^{\prime}+(1-\theta)(1+\tau) c^{\prime}}\left(\theta c(q)+(1-\theta) c^{\prime}(q) q\right) .
$$

So, the seller's surplus is given by

$$
S^{s}(q)=\frac{\omega \frac{m}{n}}{1+\tau}-c=\frac{(1-\theta) c^{\prime}}{\theta u^{\prime}+(1-\theta)(1+\tau) c^{\prime}}\left(u^{\prime} q-(1+\tau) c(q)\right),
$$

and the buyer's surplus is given by

$$
S^{B}(q)=u^{\prime} q-\omega \frac{m}{n}=\frac{\theta u^{\prime}}{\theta u^{\prime}+(1-\theta)(1+\tau) c^{\prime}}\left(u^{\prime} q-(1+\tau) c(q)\right) .
$$

\section{APPENDIX B: The Problem with Competitive Pricing}

The household's problem is now given by

$$
v(m)=\max _{\left\{q^{b}, q^{s}, \sigma_{b}, \sigma_{s}, m_{+1}\right\}}\left\{\begin{array}{c}
n \sigma_{b} A_{b}(T) u\left(q^{b}\right)-(1-n) \sigma_{s} A_{s}(T) c\left(q^{s}\right) \\
-n \phi\left(\sigma_{b}\right)-(1-n) \phi\left(\sigma_{s}\right)+\beta v\left(m_{+1}\right)
\end{array}\right\}
$$

subject to

$$
p q^{b} \leq \frac{m}{n}
$$

and the law of motion for money

$$
m_{+1}=m+(1-n) \sigma_{s} A_{s}(T) \frac{p q^{s}}{(1+\tau)}-n \sigma_{b} A_{b}(T) p q^{b}+L .
$$

The first order conditions on $q^{b}$ and $q^{s}$ and the envelope condition are given by:

$$
\begin{aligned}
u^{\prime}\left(q^{b}\right) & =\omega p+\lambda p \\
c^{\prime}\left(q^{s}\right) & =\frac{\omega p}{(1+\tau)} \\
\frac{\omega_{-1}}{\beta} & =\omega+\sigma_{b} A_{b}(T) \lambda
\end{aligned}
$$

Imposing stationarity and symmetry, the equilibrium condition is given by

$$
\frac{u^{\prime}(q)}{c^{\prime}(q)}=\left[1+\frac{1}{\sigma_{b} A_{b}(T)}\left(\frac{\gamma}{\beta}-1\right)\right](1+\tau)
$$

which is the same as with bargaining in (14). Solving for the buyer's surplus, we obtain

$$
\begin{aligned}
S^{B}(q) & =u(q)-\omega p q \\
& =u(q)-(1+\tau) c^{\prime}(q) q \\
& =u(q)-u^{\prime}(q) q+\frac{1}{\sigma_{b} A_{b}(T)}\left(\frac{\gamma}{\beta}-1\right)(1+\tau) c^{\prime}(q)
\end{aligned}
$$


and the seller's surplus

$$
\begin{aligned}
S^{S}(q) & =\frac{\omega p q}{(1+\tau)}-c(q) \\
& =c^{\prime}(q) q-c(q)
\end{aligned}
$$

\section{APPENDIX C: Lagos and Wright with Competitive Pricing}

I strictly follow Rocheteau and Wright (2005) with the addition of the sales tax paid by the seller. In that case, there is no change to the problem of the buyer and the problem of the seller becomes (numbering the equations in line with Rocheteau and Wright):

$$
\begin{aligned}
V^{s}\left(z_{s}\right)= & \alpha_{s}(n) \max _{q^{s}}\left\{-c\left(q^{s}\right)+\beta_{n} W^{s}\left(\frac{z_{s}+\frac{p q^{s}}{(1+\tau)}}{\gamma}\right)\right\} \\
& +\left[1-\alpha_{s}(n)\right] \beta_{n} W^{s}\left(\frac{z_{s}}{\gamma}\right)-k
\end{aligned}
$$

From this $c^{\prime}\left(q^{s}\right)=\beta_{n} \frac{p}{(1+\tau) \gamma}$, which leads to

$$
\frac{u^{\prime}\left(q^{b}\right)}{(1+\tau) c^{\prime}\left(q^{s}\right)}=1+\frac{\gamma-\beta}{\beta \alpha_{b}(n)} .
$$

The seller's match surplus is then:

$$
\begin{aligned}
S^{s}(q) & =\frac{\beta}{\gamma} \frac{p q}{(1+\tau)}-c(q) \\
& =c^{\prime}(q) q-c(q),
\end{aligned}
$$

and buyer's match surplus is:

$$
\begin{aligned}
S^{b}(q) & =u(q)-\frac{\beta}{\gamma} z \\
& =u(q)-(1+\tau) c^{\prime}(q) q \\
& =u(q)-u^{\prime}(q) q+\frac{1}{\alpha_{b}(n)}\left(\frac{\gamma}{\beta}-1\right)(1+\tau) c^{\prime}(q) .
\end{aligned}
$$

